УДК: 338.14

$10.17213 / 2075-2067-2019-4-99-106$

\title{
ЭКОЛОГИЧЕСКИЕ АСПЕКТЫ В СИСТЕМЕ ОБЕСПЕЧЕНИЯ ЭКОНОМИЧЕСКОЙ БЕЗОПАСНОСТИ ОРГАНИЗАЦИИ
}

\author{
(C) 2019 г. Н. Н. Катков ${ }^{*}$ М. С. Галкин **, А. А. Махно* \\ *Российский государственный аграрный университет - МСХА \\ им. К. А. Тимирязева, г. Москва \\ **Федеральный научный центр аграрной экономики и социального развития \\ сельских территорий - Всероссийский научно-исследовательский институт \\ экономики сельского хозяйства, г. Москва
}

В статье рассмотрены понятия экономической и экологической безопасности, обозначена необходимость их взаимного пересечения и функциионирование для обеспечения экологического баланса и устойчивого развития как страны в целом, так и каждого хозяйствующего субъекта в отдельности. Представлена система правового регулирования охраны окружающей среды. Предложены показатели по оченке экологической безопасности организации. Раскрыты составляющцие элементы системы экологической безопасности.

Ключевые слова: экономическая безопасность; окружающуая среда; система экологической безопасности; экологическая политика; устойчивое развитие.

In article concepts of economic and environmental safety are considered, need of their mutual crossing and functioning for ensuring ecological balance and sustainable development both the country in general, and each economic entity separately is designated. The system of legal regulation of environmental protection is presented. Indicators on estimates of environmental safety of the organization are offered. The making elements of a system of environmental safety are opened.

Key words: economic security; environment; system of environmental safety; environmental policy; sustainable development.

\section{Формулировка проблемы}

Экономическая безопасность в современной России является одной из самых обсуждаемых и актуальных тем. В рамках санкционного давления, изменения мировых политических сил, внутренних преобразований экономики обеспечение экономической безопасности становится приоритетным направлением в укреплении позиций государства в системе экономических отношений.

Экономическая безопасность страны выражается в способности поддержания и обеспечения ее суверенитета при решении вопросов, связанных с внутренними и внешними интересами государства, сохранени- ем и дальнейшим развитием экономического потенциала, а также повышением уровня жизни граждан.

Система экономической безопасности должна носить комплексный характер и включать в себя организацию экономических, правовых, технических и экологических мероприятий, что в конечном счете способствует предотвращению экономических потерь [9]. Именно последний элемент, связанный с экологическими аспектами, рассматривается в данной статье.

В настоящее время производственной деятельностью человека и продуктами труда в той или иной мере охвачено все обитаемое 
пространство нашей планеты. По оценкам аналитиков, произведенным с помощью космической съемки, оказалось, что обитаемых земель, не затронутых человеком, осталось только 28,3\%. Сохранившаяся часть природных экосистем должна выступить в виде основы для восстановления эколого-экономического баланса Земли. Глубокому антропогенному преобразованию сейчас подвергнуто более $28 \%$ поверхности суши, из которых 17\% это земледельческая площадь, включая агропоселения и окультуренные пастбища [10].

По мнению экологов, площадь антропогенного освоения уже превышает допустимый предел земельных ресурсов, подлежащих хозяйственному использованию, в том числе и для интенсивного земледелия. Пашня может быть увеличена лишь за счет пастбищ и лесов, что чревато серьезными эколого-экономическими потерями.

Международная организация Global Footprint Network опубликовала итоги своей работы, в которых указано, что начиная уже с августа 2014 года человечество выступает в роли «экологического банкрота» [12]. Это означает, что люди исчерпали все возобновимые ресурсы и в дальнейшем экологическая обстановка будет динамично ухудшаться, а это в скором времени приведет к непоправимым последствиям, которые полностью изменят условия жизни на Земле.

Сегодня мы наблюдаем конфликт между динамичным ростом мировой экономики и перегрузками, которым подвергается экосистема нашей планеты. Для того чтобы остановить разрушение нашей планеты, необходимо хищническое отношение к природе преобразовывать в кооперацию с ней, постепенно переходить от ископаемых к возобновляемым источникам энергии, от линейных производственных процессов к замкнутым циклам, от максимизации прибыли к ее оптимальной величине с сохранением экологического баланса.

Для стабилизации экологической обстановки необходимы мероприятия как глобальных масштабов (на уровне мира, страны), так и локальных, касающихся организаций и каждого человека в отдельности.

Однако, что касается России, то в настоящее время не разработаны методы развития общественного хозяйства, учитыва- ющие природно-экологическое равновесие с минимальнј вредными воздействиями на окружающую среду, поэтому необходимо принять меры по экологизации производственной деятельности страны и каждой отдельной организации.

Деятельность человека в современном мире оказывает огромное давление на окружающую природную среду, при этом влияние человечества на природу с каждым годом увеличивается, что требует выработки оперативных и эффективных способов ее восстановления и защиты, а также мероприятий по предупреждению вредного воздействия.

В области антропогенного загрязнения окружающей среды можно выделить следующие глобальные проблемы:

- сильное изменение климата Земли, причинами которого являются большие выбросы в атмосферу углекислого газа, техногенного тепла и аэрозольных примесей;

- разрушение озонового слоя нашей планеты, что также связано с поступлением в атмосферу различных веществ (окислов азота, фреонов и др.);

- экологические последствия загрязнения окружающей среды и биосферы радионуклидами, пестицидами, гербицидами и тяжелыми металлами;

- глобальное загрязнение Мирового океана и истощение ресурсов питьевой воды;

- проблема переноса загрязняющих веществ через атмосферу, и появление кислотных осадков.

Россия занимает 74-t место среди экологически чистых стран мира, при этом загрязнение окружающей среды отмечается практически повсеместно во всех промышленных регионах и городах [3]. Одной из причин данной ситуации является утрата экономического потенциала страны, низкий уровень технического прогресса в результате внедряемых реформ.

\section{Экологическая безопасность как система}

Рассмотрим, что же такое экологическая безопасность и как она связана с экономической безопасностью.

Под экологической безопасностью понимается состояние защищенности жизненно важных интересов личности, общества и государства от внутренних и внешних угроз, 
создаваемых вследствие чрезвычайных ситуаций природного и техногенного характера [8].

Это самостоятельный вид деятельности в области хозяйственного регулирования и государственного управления, тесно связанный с другими видами хозяйственно-экономических отношений и заключающийся в разрешении эколого-экономических проблем на всех уровнях. Наиболее значимыми являются проблемы земле-, лесо- и водопользования, загрязнения атмосферы в городах, утилизации и размещения токсичных промышленных отходов, хранения и уничтожения химического оружия.

Также некоторые ученые под экологической безопасностью понимают создание безопасного, экологически здорового образа жизни населения в условиях динамично развивающейся производственной деятельности с сохранением благоприятной окружающей среды и природно-ресурсного потенциала в целях удовлетворения общественных потребностей нынешнего и будущих поколений людей [9].

Экологическая безопасность как один из важнейших блоков экономической безопасности отражает не только фактическое экологическое состояние на территории страны, но и состоит в тесной органической взаимосвязи со всеми сферами и составля- ющими экономической безопасности. Так, одним из важнейших приоритетов стратегии устойчивого развития нашей страны является рациональное использование природных ресурсов и охрана окружающей среды, формирование здоровой среды обитания человека, условий для его культурного и духовного совершенствования. Экологизация экономики должна обязательно предполагать систему мер, направленную на сбалансированность действий в производственной деятельности с существующими природно-ресурсными условиями. Для обеспечения экологической безопасности государственные органы формируют систему правового регулирования охраны окружающей среды (рис. 1), которая дает комплексный подход к регулированию отношений по охране экологии.

За прошедшие годы в России было разработано и принято большое количество нормативно-правовых актов в области обеспечения экологической безопасности страны. Однако данная работа должна быть продолжена и осуществляться непрерывно с целью обеспечения экологической стабилизации государства.

Субъекты экономики, заинтересованные в повышении своей экономической безопасности, должны обеспечивать и экологическую безопасность. На уровне хозяйствую-

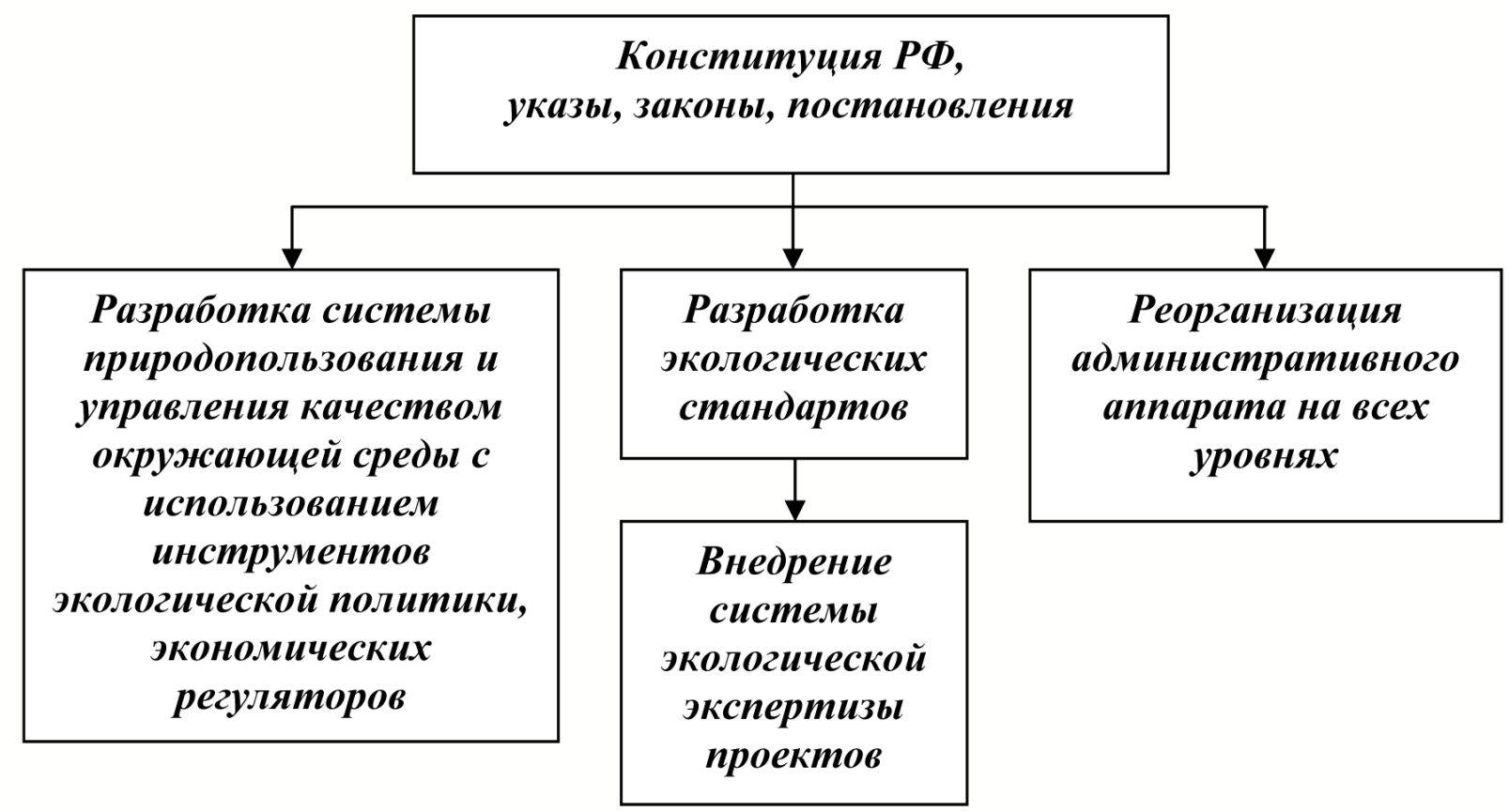

Рис. 1. Система правового регулирования охраны окружающей среды [9] 
щего субъекта экологическая безопасность представляет собой совокупность состояний и процессов, обеспечивающих экологический баланс в окружающей среде и не приводящих к жизненно важным ущербам, наносимым природной среде и человеку [3]. В настоящее время особенно актуальна проблема безопасного производства с точки зрения вреда, наносимого окружающей среде, для сельскохозяйственных предприятий.

В процессе производственной деятельности большинство организаций оказывают негативное влияние на окружающую среду. Это проявляется не только в выбросах отравляющих веществ в атмосферу, как считают многие, но и ряде других направлений. Для каждой конкретной организации перечень видов отходов различается в зависимости от ее вида деятельности.

10 января 2002 года был принят Федеральный закон «Об охране окружающей среды», где в ст. 16 сказано, что индивидуальные предприниматели и юридические лица должны вносить плату за негативное воздействие на окружающую среду за выбросы загрязняющих веществ, сбросы загрязняющих веществ, хранение, захоронение отходов производства и потребления [1]. Это обязывает организации, чья деятельность подпадает под критерии, перечисленные в законе, осуществлять соответствующие отчисления в бюджеты. Согласно Федеральному закону от 03.12.2012 г. №244-Ф3 «О внесении изменений в Бюджетный кодекс Российской Федерации и отдельные законодательные акты Российской Федерации» плата за негативное воздействие на окружающую среду зачисляется в бюджеты следующим образом [2]:

- 5\% в федеральный бюджет $+40 \%$ в бюджет субъекта РФ $+55 \%$ в бюджет муниципальных районов и городских округов;

- 5\% в федеральный бюджет + 95\% в бюджет субъекта РФ — города федерального значения.

Плата исчисляется лицами самостоятельно путем умножения величины платежной базы по каждому загрязняющему веществу на ставку указанной платы с применением коэффициентов. Лица обязаны вносить плату в бюджет в виде квартальных авансовых платежей (субъекты малого и среднего предпринимательства платят один раз в год).
Таким образом, в РФ не существует недостатка концептуальных идей по совершенствованию экологического законодательства, основной проблемой является отсутствие механизмов согласования и внедрения стимулов к развитию природоохранной деятельности, максимально учитывающих интересы различных сторон. Это требует дальнейшего развития инструментов политики по охране окружающей среды, а также совершенствования подходов и методов оценки уровня экологической безопасности на всех уровнях хозяйствования.

В целом организациям можно использовать следующие показатели для оценки экологической безопасности (табл. 1) [10].

На любом уровне функционирования экологическая безопасность проявляется в виде системы (рис. 2), под которой понимают систему мероприятий, обеспечивающих с определенной вероятностью допустимое негативное воздействие антропогенных и природных факторов экологической опасности на человека и окружающую среду.

Таким образом, мы видим, что функционально система экологической безопасности состоит из трех взаимосвязанных элементов (модулей), которые в своем единстве реализуют на практике мероприятия по защите и минимизации воздействия на окружающую среду.

Производственно-хозяйственная деятельность должна рассматриваться как целостная и сложная эколого-экономическая система, в которой переплетаются процессы различного характера: социальные, биологические, экономические, технологические и экологические. В связи с этим возникает необходимость в комплексной системе контроля за антропогенной деятельностью, т.е. организации всестороннего мониторинга окружающей среды.

Мониторинг осуществляет сбор информации, которая является научной базой для осуществления и планирования мероприятий по восстановлению естественного баланса в окружающей среде [4].

Мониторинг может осуществляться на различных уровнях. Так, например, глобальный мониторинг формирует данные по биосфере всей Земли, национальный проводится в пределах страны, региональный связан в рамках района или области, а локаль- 


\section{Показатели оценки экологической безопасности организации}

\begin{tabular}{|c|c|c|}
\hline № & Показатели & Размерность \\
\hline \multicolumn{3}{|c|}{ Базовые показатели } \\
\hline 1 & Доля используемого вторичного сырья & $\%$ \\
\hline 2 & Взысканный экологический ущерб & тыс. руб. \\
\hline 3 & $\begin{array}{l}\text { Инициативы по смягчению воздействия продукции и услуг на } \\
\text { окружающую среду и масштаб смягчения воздействия }\end{array}$ & ед. \\
\hline 4 & Инвестиции в объекты охраны окружающей среды & тыс. руб. \\
\hline 5 & Использование энергии & ГДж \\
\hline 6 & Удельное потребление энергии в натуральном выражении & ГДж/ед. продукции \\
\hline 7 & Потребление свежей воды на собственные нужды & тыс. $\mathbf{M}^{3}$ \\
\hline 8 & Удельное потребление воды & тыс. м³/ед. \\
\hline 9 & Доля повторно использованной воды на собственные нужды & $\%$ \\
\hline 10 & Выбросы парниковых газов & т в эквиваленте $\mathrm{CO}_{2}$ \\
\hline 11 & Выбросы загрязняющих веществ в атмосферу & $\mathrm{T}$ \\
\hline 12 & Удельные выбросы загрязняющих веществ в натуральном выражении & т/ед. \\
\hline 13 & Сбросы сточных вод & тыс. $\mathrm{M}^{3}$ \\
\hline 14 & Удельные сбросы сточных вод в натуральном выражении & тыс. м³/ед. \\
\hline 15 & Сбросы загрязненных сточных вод & тыс. $\mathrm{M}^{3}$ \\
\hline 16 & Объем отходов & $\mathrm{T}$ \\
\hline 17 & Удельный объем отходов в натуральном выражении & т/ед. \\
\hline 18 & Число существенных аварий с экологическим ущербом & ед. \\
\hline 19 & $\begin{array}{l}\text { Доля материалов, представляющих собой переработанные или } \\
\text { повторно используемые отходы }\end{array}$ & $\%$ \\
\hline 20 & $\begin{array}{l}\text { Энергия, сэкономленная в результате мероприятий по снижению } \\
\text { энергоэффективности }\end{array}$ & ГДж \\
\hline 21 & $\begin{array}{l}\text { Стратегии, осуществляемые действия и планы на будущее по уп- } \\
\text { равлению воздействиями на биоразнообразие }\end{array}$ & ед. \\
\hline 22 & $\begin{array}{l}\text { Доля проданной продукции и ее упаковочных материалов, возвра- } \\
\text { щаемой для переработки производителю с разбивкой по категориям }\end{array}$ & $\%$ \\
\hline 23 & $\begin{array}{l}\text { Денежное значение значительных штрафов и общее число нефи- } \\
\text { нансовых санкций, наложенных за несоблюдение экологического } \\
\text { законодательства и нормативных требований }\end{array}$ & тыс. руб. \\
\hline
\end{tabular}


ный функционирует в городах и отдельных организациях. Региональный и локальный мониторинг формирует информацию об источниках поступления и перераспределения загрязнений в конкретном регионе. На основе работы системы экологической безопасности формируются механизм и методы экономического регулирования в области охраны окружающей среды.

\section{Выводы и предложения}

Можно предложить следующие методы экономического регулирования в системе обеспечения экологической безопасности:

- разработка прогнозов социального и экономического развития государства на основе экологических перспектив;

- разработка программ федерального уровня в области экоразвития, а также формирование целевых программ для субъектов
Российской Федерации в области охраны окружающей среды;

- проведение превентивных мероприятий по сохранению и охране окружающей среды;

- установление платы за негативное воздействие на окружающую среду организациям, деятельность которых отрицательно сказывается на экологии.

Экономический механизм регулирования охраны окружающей среды необходим для формирования как у производителей, так и у потребителей бережного отношения к природе. При этом организациям целесообразно определять показатели экологической безопасности и включать их в свою отчетность. Определяя приоритеты экономической безопасности, хозяйствующим субъектам необходимо согласовывать их с приоритетами экологической безопасности. Только так будет обеспечивать-

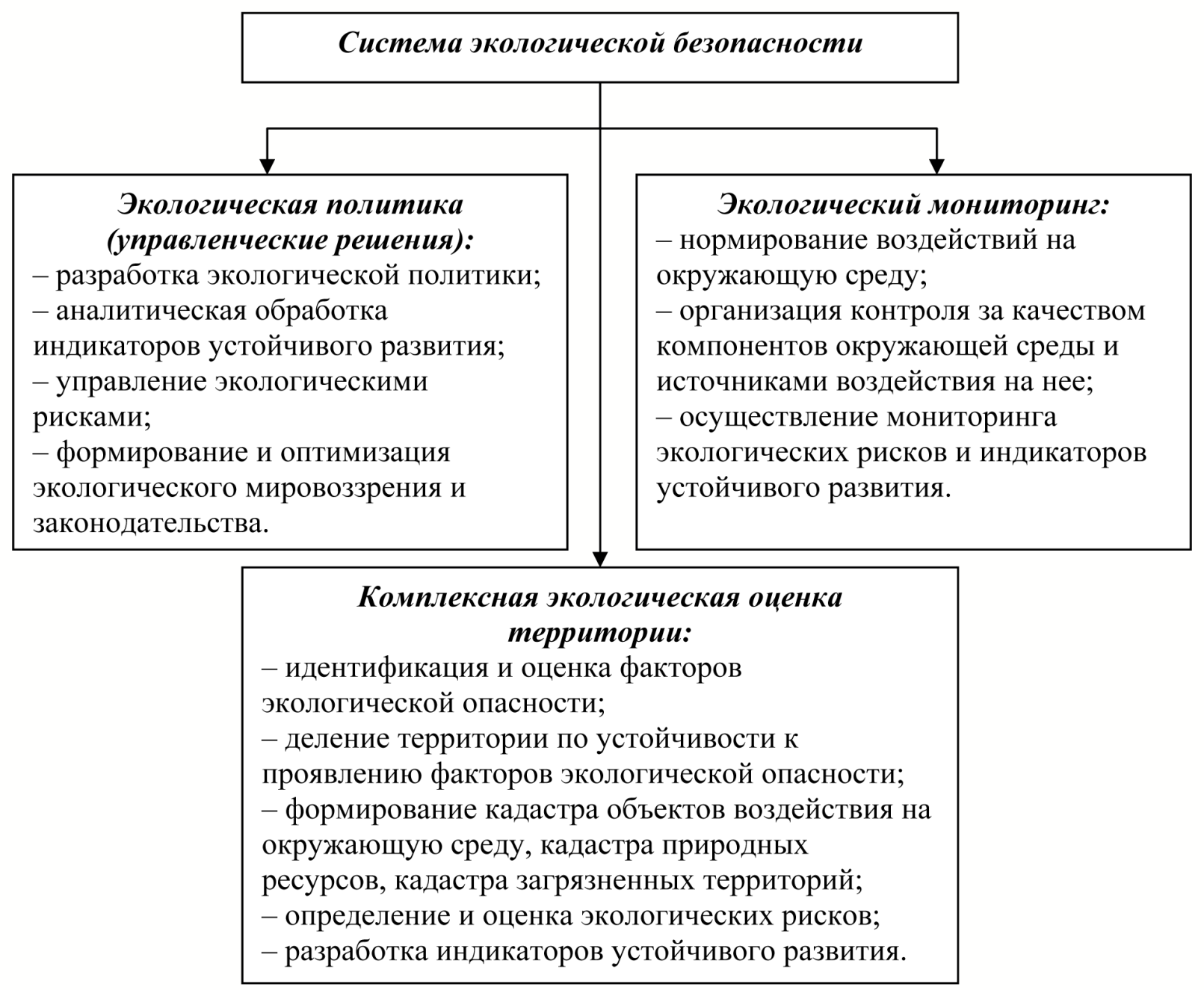

Рис. 2. Структурные модули системы экологической безопасности 
ся долгосрочное устойчивое функционирование организаций в ближайшем будущем.

Таким образом, экологическая и экономическая безопасности тесно связаны и должны функционировать в одной системе для устранения возможных противоречий и эффективного обеспечения безопасности и устойчивого развития как хозяйствующих субъектов, так и государства в целом.

\section{Литература}

1. Об охране окружающей среды: Федеральный закон от 10.01.2002 г. №7-Ф3 / Консультант Плюс [Электронный ресурс] - Peжим доступа: http://www.consultant.ru.

2. О внесении изменений в Бюджетный кодекс Российской Федерации и отдельные законодательные акты Российской Федерации: Федеральный закон от 03.12.2012 г. №244-Ф3 / Консультант Плюс [Электронный ресурс] — Режим доступа: http://www. consultant.ru.

3. Воронков Н.А. Экология: общая, социальная, прикладная. Учебник для студентов вузов. - М.: Агар, 2006. - 424 с.

4. Григорьев Д. Н., Игнатьева А.В. Экологически чистое производство - условие устойчивого развития экономики // Гуманитарное знание и образование на рубеже тысячелетий. - Екатеринбург, 2000. — С. 95-97.
5. Дафт Р. Менеджмент. 8-е изд. / Пер. с англ. под ред. С.К. Мордовина. - СПб.: Питер, 2009. - 800 с.

6. Думнов А.Д. Макроэкономическая оценка использования природных ресурсов в России / А. Д. Думнов // Вопросы статистики. - 2001. - №1. - С. 48-55.

7. Фюкс Р. Зеленая революция: Экономический рост без ущерба для экологии / Ральф Фюкс; пер. с нем. - М.: Альпина нон-фикшн, 2016. - $330 \mathrm{c}$.

8. Экономическая безопасность: учеб. пособие для студентов вузов, обучающихся по специальностям экономики и управления/ [В. А. Богомолов и др.]; под ред. В.А. Богомолова. - 2-е изд., перераб. и доп. - М.: ЮНИТИ-ДАНА, 2009. - 295 с.

9. Экономическая безопасность: учебник для вузов / под общ. ред. Л.П. Гончаренко, Ф.В. Акулинина. - М.: Издательство Юрайт, 2015. - $478 \mathrm{c}$.

10. Экономика устойчивого развития: Учеб. пособие / Т.А. Акимова, Ю.Н. Мосейкин. - М.: 3АО «Издательство «Экономика», 2009. - $430 \mathrm{c}$.

11. Freeman R. E., Pierce J., Dodd R. Shades of Green: Ethics and the Enviroment. - New York Oxford University Press, 1995.

12. Global Footprint Network [Электронный ресурс] - Режим доступа: https://www. footprintnetwork.org.

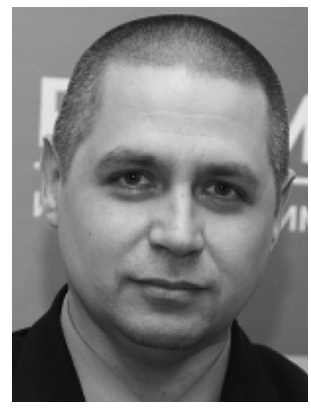

Катков Юрий Николаевич - кандидат экономических наук, доцент кафедры экономической безопасности, анализа и аудита Российского государственного аграрного университета - МСХА им. К. А. Тимирязева.

Katkov Yuri Nikolaevich - candidate of economic Sciences, associate Professor of the Department of economic security, analysis and audit of the Russian state agrarian University - Moscow Timiryazev Agricultural Academy. 


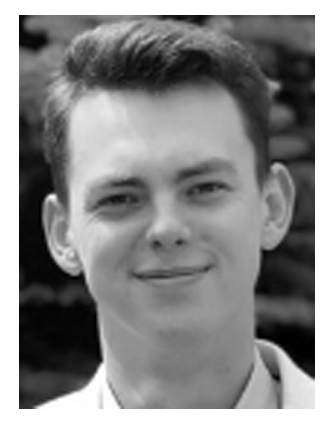

Галкин Максим Сергеевич - аспирант отдела исследования ценовых и финансово-кредитных отношений в АПК Федерального научного центра аграрной экономики и социального развития сельских территорий - Всероссийского научно-исследовательского института экономики сельского хозяйства.

Galkin Maxim Sergeevich - a post-graduate student of the Department of research of price and financial and credit relations in the agro-industrial complex of the Federal Research Center of Agrarian Economy and Social Development of Rural Areas - AllRussian Research Institute of Agricultural Economics.

123007, г. Москва, Хорошевское ш., 35, корп. 2 35 Khoroshevskoe r., bld. 2, 123007, Moscow, Russia Тел.: +7 (499) 195-60-16, факс: +7 (499) 195-60-07

E-mail: maksongal@mail.ru

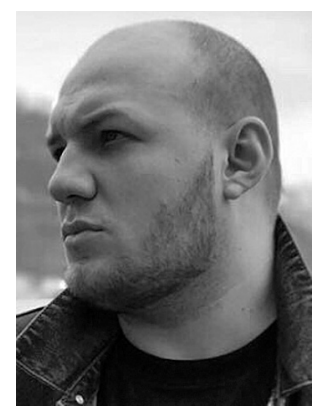

Махно Артем Андреевич - студент кафедры экономической безопасности, анализа и аудита Российского государственного аграрного университета - МСХА им. К. А. Тимирязева.

Makhno Artem Andreevich - student of the Department of economic security, analysis and audit of the Russian state agrarian University - Moscow Timiryazev Agricultural Academy.

127550 , г. Москва, Лиственничная аллея, 4, уч. корп. №2

4 Listvennichnaya alley, ed. bld. №2, 127550, Moscow, Russia

Тел.: +7 (499) 976-39-41; e-mail: artem.mahno@bk.ru 